\title{
Research on Smelting Process and Submerged arc Furnace for Silico-calcium Alloy
}

\author{
Wei LIN \\ CISDI Engineering Co., Ltd.2 \\ Chongqing, China \\ E-mail: wei.a.lin@cisdi.com.cn
}

\begin{abstract}
With the comparision of smelting process technology and submerged arc furnaces for silico-calcium alloy at home and abroad, it is seen that the development of large capacity arc furnace technology for silico-calcium alloy is necessary and urgent in China.
\end{abstract}

Keywords-Silico-Calcium Alloy; Smelting Process Technology; Large Capacity Arc Furnace

\section{INTRODUCTION}

Silico-calcium alloy is a type of composite alloy consisting of silicon, calcium and iron. With the constant development of iron and steel industry, it is more and more extensively realized that silico-calcium alloy is used for deoxidation and desulfurization in liquid steel, bringing benefits in the production of high-quality steel, special steel and special alloy [1]. With the rapid development of the liquid steel continuous casting, the calcium treatment and wire feeding technology in recent 20 years, the application of silico-calcium alloy in iron and steel industry is increasing in the world.

\section{Smelting Process AND Furnaces AT Home AND} ABROAD

Ever since 1950s, the industrial production of silicocalcium alloy began to develop in China. Silico-calcium alloy was produced by $1800 \mathrm{KVA}$ arc furnace in Shanghai Ferroalloy factory in 1960. And Chongqing Ferroalloy plant was another silico-calcium alloy producers at early stage in China. Beijing ferroalloy plant (Shougang ferroalloy Co., Ltd.) began to produce silico-calcium alloy in early 1964 and successfully innovated new technology of silicocalcium alloy smelting named "layered charging method" in October 1964. The economic index such as the power consumption and furnace lining life (longer than 1 year) achieved leading level in China and approaching the advanced level in the world. Hence the silico-calcium alloy produced by "layered charging method", which was emulated nationwide, account for about half of the total production in China in the 1960s and 1970s. But "layered charging method" process only applys to arc furnaces lower than $1500 \mathrm{KVA}$, which was negative for environmental governance and with high energy consumption. For the reason, with the restrictions of small capacity arc furnace, the "layered charging method" process need updating. Shanxi Chenghua Smelting and Chemical Corporation Ltd. invested to build a 30 MVA silico-calcium alloy arc furnace in 2009. The power consumption was $11000 \mathrm{kwh} / \mathrm{t}$, which was at the advanced level in China.

Nowadays, French BOZEL Company is still at the leading position in the overseas alloy companies whose power consumption is $9000 \mathrm{kwh} / \mathrm{t}[2]$ and smelting process can be continuous. German SKW company has the global largest capacity silico-calcium alloy arc furnace of 48 MVA, whose power consumption is $10500 \sim 10700 \mathrm{kwh} / \mathrm{t}$ and furnace lining life is more than 10 months $^{[3]}$. Norway Elkem Company has improved the 14 MVA silico-calcium alloy arc furcance with a combined electrode holders and other advanced facilities. Italy OET Company also has one set of 30 MVA calcium silicon alloy arc furnace with a furnace body rotary system whose power consumption is $10500 \mathrm{kwh} / \mathrm{t}$.

\section{Silico-Calcium Alloy Smelting Process}

Silico-calcium alloy smelting process can be divided into four types [2]: two-step process, electro-silicothermal process method, mixed charging process and layered charging process. Two-step and electro-silicothermal process are used rarely in China. On the contrary, mixed charging and layered charging process are mainly adopt to the production of silico-calcium alloy in China.

\section{A. Two-step process}

The smeliting process is based on carbon thermal process theory which needs two arc furnaces. Calcium carbide produced by one furnace is cooled and crushed, mixed with the corresponding amount of silica and carbonaceous reductant. Then the mixed material is charged into the other arc furnace for the smelting of silico-calcium alloy. The chemical reaction is listed as below:

$$
\begin{gathered}
1 / 2 \mathrm{SiO}_{2}(\mathrm{~s})+1 / 2 \mathrm{C}(\mathrm{gr})+1 / 4 \mathrm{CaC}_{2}(\mathrm{~s})=1 / 4 \mathrm{CaSi}_{2}(1)+\mathrm{CO}(\mathrm{g}) \\
\Delta \mathrm{G}^{\circ}=85063-47.35 \mathrm{~T} \quad \mathrm{~T}=1796 \mathrm{~K}
\end{gathered}
$$

The smelting process avoids the contact of $\mathrm{CaO}$ and $\mathrm{SiO}_{2}$ in terms of the charging operation, so as to solve the problem that $\mathrm{CaO}$ and $\mathrm{SiO}_{2}$ lead to the low slag temperature. In addition, more carbonaceous reductant is not needed, avoiding the pile-up of carbide in the furnace and the riseup of furnace bottom, and accordingly periodically shutdown is avoided. However, this process has some defects such as higher comprehensive power consumption, improper utilization of heat energy, higher investment and 
strict requirements. It is commonly used in Japan and former Soviet Union.

\section{B. Electrosilicothermal process}

For this process, free silica in the $75 \mathrm{FeSi}$ alloy is used to reduce $\mathrm{CaO}$ in the closed arc furnace to output silicocalcium alloy. The original phase $\mathrm{FeSi}_{n}(\mathrm{n}=2 \sim 2.5)$ of ferrosilicon react into the alloy. As a result, there are higher $\mathrm{Si}$ and Fe content and lower Ca content (only 15\% 20\%) in silico-calcium alloy. The smelting process is discontinuous on account of that it is operated to tapping alloy after all the material melting. Total power consumption of this method for the production of silico-calcium alloy (Ca 15\% 20\%) applied in Russia in the 1960s is 4000 5000 kwh/t, lower than carbon thermal process for the production of silicocalcium alloy $(\mathrm{Ca} \mathrm{30 \% ).} \mathrm{It} \mathrm{is} \mathrm{shown} \mathrm{by} \mathrm{Fig.} 1$ that the density of silico-calcium alloy (Ca 30\%) and alloy (Ca $15 \%$ ) are respectively $2.4 \mathrm{~g} / \mathrm{cm}^{3}$ and $3.3 \mathrm{~g} / \mathrm{cm}^{3}$.



Fig.1 Effect of content of $\mathrm{Ca}$ on density of silico-calcium alloy

It has been verified that steelmaking using silicocalcium alloy of larger density can enhance calcium conversion rate. One former Soviet Union steelmaking plant has good achievements in producing $2 \mathrm{Cr} 13 \mathrm{~B}$ and $18 \mathrm{Cr} 2 \mathrm{Ni} 4 \mathrm{~B}$ steel by using the silico-calcium alloy $(\mathrm{Ca}$ $12 \sim 20 \%$ ) instead of the alloy (Ca $28 \%$ ). Also it is proved to be good in the low alloyed steel production by using the silico-calcium alloy (Ca 15 18\%) in some steelmaking plants in China. The rise-up of furnace bottom is avoided by the Electro-silicothermal process.

\section{Mixed charging process}

This process is also named one step process. For this process, weighed and mixed lime, silica, coke and other carbonaceous reductant are all charged into the arc furnace to produce silico-calcium alloy by proper operation. The chemical reaction is listed as below:

$$
\begin{gathered}
1 / 5 \mathrm{CaO}(1)+2 / 5 \mathrm{SiO}(1)+\mathrm{C}(\mathrm{gr})=1 / 5 \mathrm{CaSi}_{2}(1)+\mathrm{CO}(\mathrm{g}) \\
\Delta \mathrm{G}^{\circ}=97517-49.37 \mathrm{~T} \quad \mathrm{~T}=1975 \mathrm{~K}
\end{gathered}
$$

From the thermodynamic point of view, the reaction only run when the temperature is higher than $1975 \mathrm{~K}$, which is much lower than the temperature needed by the reduction of $\mathrm{CaO}$ using $\mathrm{C}$ alone. However, $\mathrm{CaO}$ and $\mathrm{SiO}_{2}$ react to generate various forms of calcium silicate slag with high melting point. The slag only can be decomposed and reduced when the temperature is higher than $2573 \mathrm{~K}$. So the action of $2 \mathrm{CaO}+\mathrm{SiO}_{2}=2 \mathrm{CaO} \cdot \mathrm{SiO}_{2}$ dramatically reduces the reaction activity of $\mathrm{CaO}$ and $\mathrm{SiO}_{2}$ and lowers the temperature in the reaction area, making it difficult to generate silico-calcium alloy. In order to avoid this, excessive reductant need to be charged into the furnace. The chemical reaction is listed as below:

$$
\begin{array}{cr}
1 / 2 \mathrm{SiO}_{2}(1)+3 / 2 \mathrm{C}(\mathrm{gr})=1 / 2 \mathrm{SiC}(\mathrm{s})+\mathrm{CO}(\mathrm{g}) \\
\Delta \mathrm{G}^{\circ}=67035-43.86 \mathrm{~T} \quad \mathrm{~T}=1528 \mathrm{~K} \\
\mathrm{CaO}(\mathrm{s})+3 \mathrm{C}(\mathrm{gr})=\mathrm{CaC}_{2}(\mathrm{~s})+\mathrm{CO}(\mathrm{g}) \\
\Delta \mathrm{G}^{\circ}=11315-56.87 \mathrm{~T} \quad \mathrm{~T}=1957 \mathrm{~K}
\end{array}
$$

The features of mixed charging method are listed as below:

1) Easy operation;

2) Great amount of slag leads to low recovery rate of $\mathrm{Ca}$ and $\mathrm{Si}$;

3) Excessive reductant result in low specific resistance of the burden in the furnace and the difficulty of electrode inserting into the furnace burden.

4) Due to the deposition of $\mathrm{SiC}$ and $\mathrm{CaC}_{2}$, furnace bottom rises and need to stop production in a cycle. The producing cycle is about 20 30 days and 3 months respectively at home and abroad.

\section{Layered charging method}

For this process, layered charging and smelting by stages in only one set of furnace by two-step process. Firstly, raw materials are charged into the arc furnace to produce $\mathrm{CaC}_{2}$. Secondly, silica and reductant are charged into the furnace to generate calcium silicon alloy. This process avoids rise-up of the furnace bottom and the periodically shut-down, and enhances $\mathrm{Ca}$ yield rate upto $60 \% \sim 66 \%$ and Si yield rate upto $85 \% \sim 90 \%$.

\section{Silico-Calcium Alloy Smelting Arc Furnace}

\section{A. Large capacity arc furnace}

The energy and raw material consumption index of small capacity arc furnace are higher than that of large one. The disadvantage of small and medium-sized arc furnace are low temperature in the furnace, difficult decomposition of carbide, rise-up of furnace bottom, periodical shut-down. The power consumption of small size arc furnace is about $14000 \sim 15000 \mathrm{kwh} / \mathrm{t}$. By contrast, the power consumption of large capacity arc furnace larger than 10MVA furnace at home and abroad is lower than $12000 \mathrm{kwh} / \mathrm{t}$.

Domestic experimental practice also proved the advantages of large capacity calcium silicon arc furnace. The power consumption of Shanxi Chenghua 30 MVA arc furnace is about $11000 \mathrm{kwh} / \mathrm{t}[3]$. The Jilin ferroalloy plant produced silico-calcium alloy using 16.5 MVA arc furnace whose power consumption is $12000 \mathrm{kwh} / \mathrm{t}$. The silico- 
calcium alloy produced by 16.5MVA furnace containing $\mathrm{Ca}$ $28 \%$, Si $60 \%$, C $1.1 \% \sim 1.2 \%$. Finally the rise-up of the furnace bottom is not found in Shanxi Chenghua 30 MVA arc furnace and Jilin 16.5MVA arc furnace.

\section{E. Layered charging process applied into large capacity arc furnaces}

According to the relevant papers [2], one German ferroalloy company produced silico-calcium alloy by layered charging process in large capacity furnace whose power consumption is $12100 \mathrm{kwh} / \mathrm{t}$. According to the theory and the practice of layered charging process, the process can achieve excellent economic and technical index. However it is only applied in small capacity furnace at home because it is difficult to operate in the large furnace by this process. So it is necessary and urgent to do research on silicocalcium alloy furnace, operation, selection of reductants, etc for widespread use of the layered charging process in the large and medium capacity arc furnace in China.

\section{CONCLUSIONS}

1) Layered charging process avoids rise-up of furnace bottom and periodical shut-down. The process can achieve good economic and technical index.

2) Consumption index of energy and raw material for large capacity arc furnaces are lower than that of small one. Development of large capacity furnace is a trend in the future.

3) It is necessary and urgent to research and promote applying layered charging process into large capacity silicocalcium alloy furnaces.

\section{REFERENCES}

[1] ZHAO Naicheng, ZHANG Qixuan et al. Ferroalloy production practical technical manuals, Beijing: MetallurgyIndustry Press, 2003,: 31 35

[2] G. walcott, K.D Frank et al. Ferroalloy metallurgy, Shanghai: Shanghai science and technology press, 1978,: 71 92

[3] XU Luming, XU Hui. Silicon ferroalloy production technology, Beijing: Chinese society for metals press, 1980,: 55 56 